\title{
PLANO DE PREVENÇÃO E PROTEÇÃO CONTRA INCÊNDIO: UMA REVISÃO PRELIMINAR DA LITERATURA NACIONAL
}

\author{
Jennifer Vargas Caron ${ }^{1}$ \\ João Carlos Souza ${ }^{2}$
}

\section{RESUMO}

O presente artigo consiste em uma revisão da literatura sobre a utilização e aplicação do Plano de Prevenção e Proteção Contra Incêndio, não apenas para o cumprimento de normativas, mas principalmente como uma ferramenta que deve ser empregada pelos projetistas como medidas de mitigação e controle de incêndios em edificações. $O$ estudo foi desenvolvido por meio de levantamentos bibliográficos com o objetivo de identificar como ocorre a Segurança Contra Incêndio no Brasil e como o uso de projetos prescritivos ou projetos baseados em desempenho poderiam ser aplicados. Ao longo do estudo foram identificados os envolvidos neste processo e como cada participante pode atuar para garantir edificações mais seguras. Por fim, apontase quais os pontos devem ser melhorados para a elaboração de um plano de Prevenção e Proteção Contra Incêndio eficaz para a sociedade, bem como, esta deve atuar na fiscalização e cobrança para que os procedimentos sejam adequadamente aplicados.

Palavras-chave: Projeto prescritivo; projeto baseado em desempenho, responsabilidade social.

1 Mestranda em Arquitetura e Urbanismo pela Universidade Federal de Santa Catarina, Engenheira e Segurança do Trabalho pela Universidade do Sul de Santa Catarina, Arquiteta e Urbanista pela Universidade do Estado de Santa Catarina. Email: jennifer_arq@yahoo.com.br

2 Doutor, Professor e Orientador no Programa de Pós-Graduação em Arquitetura e Urbanismo da Universidade Federal de Santa Catarina, e-mail: joao.carlos@ufsc.br 
THE FIRE PREVENTION AND PROTECTION PLAN:

\title{
A PRELIMINARY REVIEW OF NATIONAL LITERATURE
}

\begin{abstract}
This paper is a literature review on the use and application of the Fire Prevention and Protection Plan, not only for normative compliance, but mainly as a tool that should be used by the designers as mitigation measures and fire control in buildings. The study was developed through bibliographic surveys with the goals of identifying how Fire Safety in Brazil occurs and how the use of prescriptive design or performance-based design could be applied. Throughout the study, those involved in this process have been identified alongwith their possible actions to ensure safer buildings. Finally, the topics that should be improved for the elaboration of an effective Fire Prevention and Protection Plan are pointed out along with suggestions of how the society should act regarding the inspection and demand in order to have the procedures properly applied.
\end{abstract}

Keywords: Prescriptive design; Performance-based design, Social responsibility.

Artigo Recebido em 28/11/2018 - Aceito em 28/03/2019 - Publicado em 31/03/2019 


\section{INTRODUÇÃO}

A segurança das pessoas, a preservação do patrimônio, a sustentação estrutural e a garantia de que as pessoas escapem com vida em situações de sinistros são os objetivos principais da Segurança Contra Incêndio (SOUZA, 1996). Esta, deve ser apurada em todas as etapas envolvidas no processo produtivo e no uso do edifício, contudo, na fase de projeto a questão deve ser especialmente considerada, devido ao fato de ser o momento no qual se estabelece a estrutura básica da segurança contra incêndio (BERTO,1998).

Souza (1996) apresenta, de forma clara, os objetivos principais da Segurança Contra Incêndio e a afirmação de Berto (1998) complementa que essas questões devem ser planejadas no projeto, visto que um sistema de proteção contra incêndio e pânico corretamente projetado e executado é fundamental para manter uma edificação segura, sendo também, uma das exigências para a liberação do Habite-se* do imóvel pelo Corpo de Bombeiros Militar (CBM).

Contudo, para que esse sistema funcione de maneira assertiva é necessário que se sigam, durante a elaboração do Projeto Preventivo Contra Incêndio e Pânico, normas prescritivas, estudos e métodos de prevenção contra incêndio. Os códigos de prevenção contra incêndio determinam as observações e exigências que devem ser atendidas, mas podem também basear-se no desempenho da edificação e no comportamento dos ocupantes no momento de um sinistro (CARLA; SILVA, 2003). Essas diretrizes são fundamentais para que se atenda aos critérios de segurança e se garanta a existência de uma estrutura específica que permita a saída dos usuários e o resgate do Corpo de Bombeiros durante uma ocorrência.

* Habite-se neste texto é usado como termo genérico do documento que atesta que o imóvel encontra-se regular perante as normas estaduais de segurança contra em incêndio. Em alguns Estados é chamado de Atestado de Regularidade (AR), em outros de Atestado de Vistoria do Corpo de Bombeiros (AVCB). 
No decorrer do texto, com base na análise de outros autores irá se discorrer sobre o uso do Plano de Prevenção e Proteção Contra Incêndio no Brasil, e se este vem sendo planejado de maneira eficiente para que garanta os objetivos fundamentais da Segurança Contra Incêndio nas Edificações. Por conseguinte, identificar-se-á se existe um método mais adequado para a concepção de Projetos Preventivos Contra Incêndio e Pânico (PPCl), e se existe, entender o porquê deste método não estar sendo implantado.

\section{REFERENCIAL TEÓRICO}

Com a evolução da sociedade, houve o nascimento de organizações para atenderem as questões de moradia, alimentação, segurança, entre outras. Surge também a organização do Corpo de Bombeiros, criada para assegurar a proteção da vida e do patrimônio físico contra os incêndios (CARDOSO, 2014).

No começo as organizações de bombeiros aprenderam com a perda de muitas vidas, e se adaptaram aos desafios dos complexos modelos sociais, criando disciplinas, corpos de artes e práticas voltadas à prevenção de incêndios e a redução dos danos causados por ele (CARDOSO, 2014).

Com o passar do tempo, e com os acontecimentos de desastres devido a incêndios, o poder público teve que pensar em maneiras para preveni-los e combatê-los. E assim surgiram os códigos de incêndios com base nas experiências do passado, que ficaram conhecidos como Códigos Prescritivos (DUARTE, 2002).

Essas regras prescritivas no início eram bastante simplificadas, restringindo-se ao uso de hidrantes e extintores nas edificações, porém na década de 70, com a ocorrência dos incêndios trágicos nos Edifícios Andraus (1972) e Joelma (1974) que resultaram na morte de centenas de pessoas, houve a comoção da opinião pública e com isso o acendimento de debate sobre a segurança contra incêndios em edifícios. Esses debates suscitaram em uma mudança significativa nas exigências, uma vez que os motivos que 
permitiram que os episódios alcançassem grandes proporções referiam-se à falta de escadas de emergência, paredes e portas corta-fogo, sinalização de rotas de fuga e saídas de emergência e a ocorrência da propagação vertical do fogo devido à fachada envidraçada do Edifício Joelma (TAVARES; CARLA; SILVA, 2002).

Todavia, as exigências de Segurança Contra Incêndio e Pânico faziam parte de um processo burocrático e político, e foi no ano de 2001 que o Estado de São Paulo deu um passo importante para a evolução destas regras, estabelecendo a ampliação da competência do Corpo de Bombeiros da Polícia Militar, passando a normatizar diretamente, através da expedição de Instruções Técnicas (IT), as exigências das medidas de SCIP(SEITO et al., 2008).

Essas normas, estudos e métodos de Prevenção Contra Incêndio evidenciam que os ambientes construídos devem ter um adequado $\mathrm{PPCl}$, a fim de atender os critérios de segurança e garantir a existência de uma estrutura específica.

Ono (2007) diz que um projeto adequado permite a saída dos usuários que estão em áreas de risco em um mínimo espaço de tempo. E o nível de facilidade para a saída vai depender do grau de risco, do tipo de construção, das características dos ocupantes e dos sistemas de proteção existentes, além disso, um bom projeto de saídas de emergência permite que às equipes de salvamento e combate ao fogo entrem com facilidade no edifício.

A saída dos ocupantes e o acesso do Corpo de Bombeiros em uma edificação tomada por chamas, fumaça ou desabamentos é um ponto chave para o sucesso das operações de resgate. Ono (2007) também relata que nos últimos 20 anos tem aumentado estudos que consideram modelos computacionais para simular e estimar o tempo de abandono em edificações.

Moser (2018) fez simulações utilizando um programa computacional em três edificações históricas. A simulação se deu a partir de um software baseado em desempenho, especificamente para o estudo da evacuação de pessoas nas edificações escolhidas. Obtendo-se o tempo de evacuação e a distância a ser 
percorrida pelo usuário, além de serem verificadas as interações entre as pessoas e a arquitetura de cada edifício. Com os resultados das aplicações, fizeram-se as comparações e análises entre a instrução técnica e a simulação, possibilitando identificar se a norma prescritiva contribui para auxiliar na adoção de medidas alternativas quando da impossibilidade de aplicação daquelas previstas.

Contudo no Brasil, assim como em outros países, as normas e recomendações ao $\mathrm{PPCl}$ são baseadas no padrão normativo caracterizado como prescritivo. Este sistema consiste em exigências detalhadas e padronizadas para diversas opções de uso e área do edifício. Mesmo sendo de fácil utilização, esse sistema torna-se inflexível, visto que não permite soluções alternativas e limita a aplicação de inovações tecnológicas, e por consequência dispensando a qualificação profissional (SERPA, 2009).

Por isso, muitos projetistas consideram a segurança contra incêndios como uma questão de atendimento a códigos e legislações. Todavia, é de responsabilidade dos profissionais da área o domínio dos conceitos de prevenção contra incêndio, para poderem projetar de modo mais seguro e econômico, levando em consideração as peculiaridades dos edifícios e não só o cumprimento mínimo dos requisitos de segurança impostos (SOUZA, 1996).

ToreroO (2011) afirma que com as inovações do ramo da construção civil, muitos projetos não se enquadram no âmbito abrangido pelas normas prescritivas da proteção contra incêndio. Assim é essencial que os projetistas tenham ciência das limitações das normas, das regulamentações e dos ensaios padronizados de maneira a poder discernir entre: os casos em que é adequado recorrer somente a métodos prescritivos; os casos em que é necessário realizar uma análise completa com base no desempenho; e os casos em que se pode utilizar os métodos prescritivos como ferramentas para pôr em prática uma estratégia baseada no desempenho.

De tal modo é fundamental que o edifício possua meios de combater de imediato o princípio do incêndio, e ainda rotas de fugas e sistemas de 
orientação e alarme que possibilitem a evacuação das pessoas em tempo hábil e sem pânico, que muitas vezes é o responsável pela maior parte de vítimas em locais de grande público. Entende-se que o conceito de edificação segura, garante que a edificação, por si só, é planejada para permitir a extinção do princípio de incêndio e se auto proteger, impedindo a propagação do calor (SOUZA, 1996).

Outra questão ainda é o fato de que na maioria das vezes o $\mathrm{PPCl}$ é realizado por um profissional que não acompanha as alterações do projeto arquitetônico e demais projetos complementares, ocasionando uma constante ocorrência de projetos que não garantem a segurança da edificação e diferem da real execução na obra. Essa incompatibilidade do $\mathrm{PPCl}$ quase sempre será percebida no momento em que o vistoriador do Corpo de Bombeiros realiza a inspeção para a entrega do Habite-se, o que gera atrasos e gastos para empreendedores, projetistas e retrabalho nos órgãos públicos.

E com a iniciativa de solucionar esses problemas, encontrados nos métodos prescritivos, começa a ser estudado o conceito de projeto baseado em desempenho. Este baseia-se em critérios pré-formulados para um produto, sem considerar a sua forma ou os materiais que o constituem, mas com base nas exigências dos usuários, ou seja, a edificação é avaliada considerando todos os aspectos (CONCEIÇÃO, 2006).

Robertson (2005) define o projeto baseado em desempenho como uma abordagem de engenharia para projetar elementos em uma edificação, com embasamento em metas e objetivos de desempenho, análise de engenharia, medições científicas e avaliação quantitativa usando ferramentas, metodologias e critérios de desempenho.

No Projeto Baseado em Desempenho em vez de garantir que o edifício atenda a uma lista de requisitos prescritivos, é avaliado como a estrutura e seus ocupantes irão se comportar na ocorrência de um incêndio. Isso significa que o projetista deve estar familiarizado com os princípios de comportamento, 
desempenho estrutural, resposta humana e sistemas de segurança de vida e proteção contra incêndios (ROBERTSON, 2005).

O Projeto Baseado em Desempenho é fundamentado em três elementos: os códigos de desempenho, as diretrizes e orientações técnicas e as ferramentas de projeto e cálculo [...](SERPA, 2009).Este modo de projetar possibilita uma maior flexibilidade, assim permite adaptações e mudanças, considera ainda a investigação de soluções e comparações entre alternativas, ou seja, transforma dados definidos na criação do projeto em objetos concretos (SERPA, 2009).

Este método foi aceito inicialmente por países como Austrália, Canadá, Nova Zelândia, Suécia, Japão e China - que descobriram que o "código baseado em desempenho" permitia maior ousadia e criatividade para os projetistas, visto que a geometria do edifício aceita as necessidades específicas de cada cliente sem precisar das limitações impostas por um projeto que deve atender as normas prescritivas (ROBERTSON, 2005).

Os requisitos e critérios baseados no desempenho da edificação frente à segurança contra incêndio são constituídos considerando a sequência de etapas possíveis na ocorrência de um sinistro: início do fogo, crescimento no ambiente de origem, propagação para outros ambientes da edificação, combate ao fogo, evacuação do edifício, propagação para outros edifícios e ruína parcial ou total do edifício. Deve-se levar em conta também as atitudes dos usuários: baixa probabilidade de início de incêndio, alta probabilidade de os usuários sobreviverem sem sofrer qualquer prejuízo e reduzida extensão de danos à propriedade e à vizinhança adjacente(CONCEIÇÃO, 2006).

Todavia para o analista que deve aprovar o projeto a tarefa torna-se difícil, visto que este deve verificar se o profissional (arquiteto / engenheiro) desenvolveu critérios baseados em desempenho que permitirão que a edificação resista aos estragos do fogo. $O$ analista deve entender sobre as capacidades do sistema de supressão, capacidade de reação humana e 
retenção antecipada de integridade estrutural em caso de incêndio. Em praticamente todos os casos, uma combinação dessas questões deve ser considerada na decisão final quanto à adequação do projeto. Se alguma parte do sistema falhar, haverá apenas o "bom senso" do analista que aprovou o projeto, pois nenhuma violação peculiar do código pode ter colaborado para o incidente (ROBERTSON, 2005).

Assim, muitos bombeiros e responsáveis pela execução da obra não se sentem à vontade para dirigir a aplicação de um código baseado em desempenho. Eles sentem que estão em terreno muito mais firme ao usar um código de tipo prescritivo(ROBERTSON, 2005).

Percebe-se que na teoria o Projeto Baseado no Desempenho é mais completo e se preocupa com outras questões que não estão presentes nas normas prescritivas, e ainda é flexível nos casos em que não é possível aplicar a norma. Contudo, ele ainda oferece muitos riscos para quem projeta e aprova. Quais ferramentas estão sendo desenvolvidas para minimizar estes riscos? Será este, um dos motivos de este método não ser utilizado no Brasil?

\section{A SEGURANÇA CONTRA INCÊNDIO E A PROPAGAÇÃO DO PROJETO BASEADO EM DESEMPENHO NO BRASIL}

No Brasil, os engenheiros, arquitetos, técnicos e estudantes que completaram o ensino médio têm conhecimento dos conceitos de: condução, radiação, convecção e de calor latente, entretanto dificilmente esses conceitos são ligados à Segurança Contra Incêndio.

As universidades também não especializam os engenheiros e arquitetos com matérias relacionadas à segurança contra incêndio porque segundo Seito et al., (2008), os currículos das faculdades de arquitetura e engenharia têm um conteúdo extenso e apertado, não permitindo absorver outros conhecimentos, sendo necessária uma profunda reformulação para que a segurança contra incêndio seja implementada. 
Assim os profissionais da área apresentam deficiências naquilo que projetam, constroem e aprovam, incidindo em perigo oculto em edificações dispostas por todas as cidades. Contudo, a legislação exige mais dos profissionais, os quais precisam se especializar para dominar a área ou contratar serviços terceirizados.

Segundo Seito et al. (2008), no país a arquitetura e o urbanismo ainda não têm a questão da segurança contra incêndio absorvida plenamente nas práticas de projeto e construção. As novas tecnologias de materiais estruturais, vedações, revestimentos, etc., encontram-se em situações de risco, visto à falta de profissionais formados especificamente para projetarem edifícios seguros contra incêndio e pânico; a falta de laboratórios completos; de legislação em nível nacional, estadual e municipal; técnicos, instaladores, operadores de sistemas; toda a produção nacional de materiais de construção ensaiada e catalogada; etc.

Essa carência na formação de engenheiros e arquitetos com relação à segurança contra incêndio é percebida quando os PPCl's são submetidos à aprovação do Corpo de Bombeiros Militar. É rotineiro que os profissionais que se aventuram a projetar nesta área contem com o aprendizado acumulado durante o processo de análise dos projetos, depois de seguidos retornos com as pendências observadas pelos analistas das corporações militares em todo o país (SILVA, 2017).

Dessa forma, os profissionais que atuam na área aprendem com a prática e com seus erros no momento da análise do projeto, porém a concepção do $\mathrm{PPCl}$, não se resume em seguir as normativas previstas pelo Corpo de Bombeiros, visto que outros fatores devem ser levados em consideração. Portanto, o projeto garantiria maior segurança aos usuários se os projetistas tivessem formação adequada, entendendo o funcionamento do fogo e os motivos para o cumprimento das normativas.

Percebe-se que algumas dúvidas levantadas pelos projetistas, quando contestam as incoerências projetuais, são em relação ao "por que" das 
Revista Científica do Corpo de Bombeiros Militar de Pernambuco

Artigo publicado no Vol.05 Nº12 - Edição de JAN a JUN 2019 - ISSN 2359-4829

Versão on-line disponível em: http://www.revistaflammae.com.

exigências das normas, e por quais motivos não pode ser de outra forma. As normativas definem o "como" deve ser, contudo não apresentam o "por que" dessas exigências.

A maioria das instruções normativas disponíveis pelos Corpos de Bombeiros de cada Estado apresentam exigências de local apropriado para instalação, distância entre os itens, quantidade necessária, entre outros, porém, é no momento do projeto que surgem dúvidas. Será que quando a norma diz no máximo vinte metros e o projetista precisar de vinte e cinco metros, este PPCl será indeferido por não atender a norma ou por não garantir a segurança na edificação? E se este projetista entendesse os motivos de a norma permitir até vinte, ele não poderia propor alterações que mesmo com vinte e cinco permitiriam a proteção contra incêndios?

Hahnemann et al (2017) ressalta que há também o método Gretener como ferramenta para avaliação de risco de incêndios em edificações. Este método visa encontrar um fator de segurança global através de cálculos matemáticos, que utilizam variantes que geram uma pontuação. Como exemplos para estas variantes tem-se a formação de brigadas de incêndio, qualidade do corpo de bombeiros local, distância do edifício ao quartel mais próximo, a existência de constante vigilância no edifício, entre outros. Se esse fator global é igual ou maior que 1,00, o edifício pode ser considerado seguro. Dessa forma, mesmo que o edifício perca pontos em uma das variantes, é possível compensar aumentando a qualidade, ou seja, a pontuação de outra.

A falta de conhecimento dos projetistas pode gerar ainda outros riscos, que por vezes podem ainda não estarem previstos nas normativas, não sendo exigências legais. De acordo com Seito et al. (2008), no momento as edificações estão admitindo riscos, sendo importante utilizar métodos de análise de riscos para garantir melhores resultados na Segurança Contra Incêndio, visto que há mais recursos investidos. Outras formas de avaliar os riscos seriam por meio da modelagem matemática pelo uso de probabilidade de ocorrência de fatores em série ou paralelo para a ocorrência de incêndio; 
análise de locais de riscos específicos; cálculos de carga de incêndio, velocidade de propagação; cálculo de perdas, tanto humanas, como materiais, operacionais, etc.; probabilidade de o incêndio passar para edifícios vizinhos, alcançando uma escala urbana.

Nas corporações de bombeiros dos Estados Unidos, por exemplo, o uso de programas de computador tem facilitado e permitido avaliar com mais precisão os riscos. Robertson (2005) afirma que os computadores são importantes para o gerenciamento de serviços de incêndio. Esses dispositivos permitem que os analistas escolham as melhores direções ao planejar a segurança contra incêndio dentro de uma comunidade. Da mesma forma, eles desempenham um papel na pesquisa de proteção contra incêndios, visto que é um instrumento que fornece ao pesquisador informações precisas sobre probabilidades que podem ser difíceis de ensaiar em laboratórios de pesquisa. Porém, é necessário que os bombeiros sejam capacitados para o uso desses programas.

Malkawi (2005) diz que as pesquisas na área são desenvolvidas por estudantes, instituições governamentais e empresa, e que estas pesquisas estão em andamento e beneficiam aumentos na informática, tais como a quebra de paradigmas de programação e o uso da internet. Ele aborda também a importância de uma interface simples a ser utilizada em projetos, para a utilização tanto de pessoas com muita ou pouca experiência.

Há ainda outras variáveis de riscos encontrados na Segurança Contra Incêndio, por exemplo, os que um projeto mal dimensionado pode causar, e que são possíveis de passar despercebido pela análise do PPCl. Alguns desses riscos somente serão identificados na Vistoria do Habite-se do imóvel acarretando novas mudanças no projeto e retardando o processo de aprovação da edificação.

Um exemplo de perigos gerados no projeto é com relação à escolha dos materiais utilizados principalmente nos acabamentos que aumentam ainda mais a carga de incêndio,visto que, faltam também estudos de resistência ao 
fogo dos materiais novos, já que não há incentivos para que se pesquisem os efeitos da combustão destes materiais, e assim prevenir as consequências que estes podem causar ao queimar.

A escolha dos materiais na concepção do projeto é fundamental para que não ocorram tragédias, como aconteceu na Boate Kiss em Santa Maria no Rio Grande do Sul. Segundo G1.GLOBO (2013), as mortes dentro da Boate Kiss foram causadas por asfixia e conforme a perícia realizada, a espuma utilizada para o isolamento acústico que revestia o teto e algumas paredes era feita de poliuretano, o que liberou gases tóxicos durante a combustão, responsáveis por causar a morte de pelo menos 234 vítimas, conforme o laudo da necropsia.

Como ressaltado ao longo desse texto, no Brasil as normas prescritivas sofrem mudanças na medida que tragédias ocorrem, e assim novamente após a ocorrência do incêndio na Boate Kiss foi sancionada a Lei Federal $n^{\circ} 13.425$, de 30 de março de 2017, que apresenta como pontos principais a qualificação de bombeiros militares que agem na fiscalização e aprovação dos PPCl; a inclusão da disciplina de prevenção contra incêndio nos cursos de engenharia e arquitetura que deveriam ter sido adicionadas até seis meses contados da entrada em vigor desta Lei; $O$ estabelecimento de novas exigências para locais com ocupação de mais de 100 pessoas, entre outros.

Passado mais de um ano após a aprovação da legislação, ainda não são perceptíveis as mudanças provocadas por ela. Vieira (2018) diz que é necessário um regulamento para operacionalizar a Lei, determinando aos órgãos de fiscalização de exercício das profissões, no caso de inclusão de disciplinas nos cursos de engenharia e arquitetura, medidas para cumprimento da obrigação, com auxílio do Ministério da Educação. Já com relação à qualificação de bombeiros militares o regulamento deve tratar da atuação conjunta da Secretaria Nacional de Segurança Pública nas ações de capacitação continuada. 
Há ainda outros fatores que são identificados no atual cenário nacional com relação à engenharia de segurança contra incêndios, como as dificuldades para que ocorra a implementação de códigos baseados no desempenho da edificação frente a ocorrência de um sinistro.

Com isso, Tavares et al (2002) listam alguns pontos a serem observados que dificultam a implementação de projetos baseados em desempenho, como:

- Poucos códigos prescritivos no Brasil;

- Pouca percepção ao risco de incêndios por parte da sociedade brasileira;

-Formação acadêmica precária na área da Engenharia de Segurança contra Incêndio;

- Legislação (normas regulamentadoras, códigos de bombeiros, etc.) pouco conhecida, bem como pouco cumprida;

- Extensão territorial bastante grande, o que dificulta ainda mais a centralização do código.

A utilização de Projetos Baseados em Desempenho conseguiu ser aplicado em países que possuem códigos prescritivos bem avançados, os quais puderam ser utilizados como referência para a comparação entre as recomendações prescritivas e as de desempenho. No entanto, como visto anteriormente, o Brasil não se enquadra nesse contexto, o que inviabiliza a implementação de um código baseado no desempenho. E mesmo com as desigualdades encontradas nos códigos de segurança contra incêndio nas diversas regiões do país (que são justamente códigos prescritivos), estes continuam sendo os mais adequados à realidade do País (TAVARES; CARLA; SILVA, 2002).

Contudo, a Segurança Contra Incêndio e Pânico é essencial para a incolumidade das pessoas, do patrimônio e do meio ambiente, devendo ser coberta pelo Estado através dos Corpos de Bombeiros, mas também com a participação da sociedade, e principalmente iniciando pelos projetistas, proprietários de imóveis ou responsáveis pelo uso, sendo a educação vital 
Revista Científica do Corpo de Bombeiros Militar de Pernambuco

Artigo publicado no Vol.05 Nº12 - Edição de JAN a JUN 2019 - ISSN 2359-4829

Versão on-line disponível em: http://www.revistaflammae.com.

nesse processo (SILVA, 2017). E iniciando com a educação será possível conscientizar uma maior parcela da população e permitir a participação de todos os envolvidos.

\section{A participação dos envolvidos}

A Segurança Contra Incêndio jamais será realizada com excelência se estiver sujeita somente a ação dos Corpos de Bombeiros, conquanto dependa dessas corporações enquanto representantes do Estado para o seu exercício (SILVA, 2017). Para isso, as pessoas devem conhecer quais condutas provocam incêndios, a fim de saberem como deveriam reagir no eventual surgimento desse sinistro. Quando percebe-se isso, fica evidente a precisão da educação pública no processo de envolvimento da sociedade na prevenção contra incêndio e pânico, não somente por meio de palestras ou treinamentos esporádicos, como ocorre no Brasil (SILVA, 2017).

Contudo, SEITO et al., (2008) afirma que o importante seria que a educação ocorresse em todos os níveis de cursos, desde a pré-escola até o terceiro grau, assim faria parte do aprendizado natural de maneira que todos saberiam quais atitudes tomar para evitar e como agir em casos de incêndios.

Diamantes (2014) apresenta algumas metas sugeridas pelo professor Lucht para reduzir a taxa de mortalidade por incêndios, que seriam a aplicação das leis de segurança contra incêndios, a atualização das leis; a educação pública especialmente para os grupos mais vulneráveis, como crianças e idosos; e os financiamentos de pesquisa. De tal modo, um programa com estas metas está em andamento em Scottsdale, Arizona, Condado de Prince George, Nova York. Este plano mostra como as comunidades necessitam de orientação e que somente através do interesse da comunidade, liderado pelo serviço de bombeiros, os problemas de incêndio do país podem ser resolvidos. 


\section{RESULTADOS}

Após o levantamento da bibliografia sobre o tema, foi possível identificar alguns pontos que devem ser melhorados para a garantia de edificações seguras para a sociedade, e consequentemente a melhoria na elaboração de PPCl's, agilidade na análise dos respectivos projetos e consequentemente na garantida da segurança contra incêndio para os usuários em geral.

Inicialmente, os erros encontrados nos projetos poderiam ser mitigados principalmente com a qualificação profissional, que inclusive proporcionaria oportunidades ao profissional.

Uma das oportunidades de um profissional devidamente qualificado na área de prevenção contra incêndios seria a prestação de serviços de assessoria e gerenciamento das atividades de manutenção das edificações no que tange os itens descritos no PPCl, realizadas após a liberação do Habite-se ao longo dos anos.

Outro método eficaz para diminuir erros de projetos é elaborar um checklist, que pode ser disponibilizado ao arquiteto como parâmetro inicial do projeto, e também poderá constituir em uma importante ferramenta de verificação e validação do projeto após seu recebimento pela construtora (NARLOCH;LIMA;SOUZA, 2014).

O Corpo de Bombeiros Militar pode utilizar como instrumento a realização de campanhas e treinamentos em escolas para propiciar a segurança e prevenção contra incêndios nas comunidades.

Os proprietários dos imóveis, podem também aplicar outras medidas de segurança, como os planos de emergência que garantem a efetiva ação dos envolvidos em caso de sinistro. Com a capacitação de Brigadistas dentro do estabelecimento, o proprietário do imóvel minimiza ainda mais as chances de ocorrerem sinistros, devido à garantia da manutenção e fiscalização dos equipamentos de $\mathrm{SCl}$ realizadas pelos brigadistas. 
Por fim, são diversos fatores que garantem um ambiente seguro contra sinistros, desde um projeto ideal, uma perfeita execução de obra, normas atualizadas, população treinada, planos de emergência e por fim Bombeiros Militares habilitados para o combate de incêndios em casos que não for possível a prevenção.

\section{CONCLUSÃO}

O emprego do Plano de Prevenção e Proteção Contra Incêndio como ferramenta para prevenir, mitigar e controlar o sinistro em uma edificação e não somente por ser uma exigência para a liberação dos imóveis foi a motivação para a concepção deste artigo. Assim, através da revisão do assunto abordado por autores de referência, foram apresentadas as principais dificuldades e desafios relacionados à $\mathrm{SCl}$ no Brasil e como é a aplicação de projetos prescritivos ou baseado em desempenho.

Com base nesse levantamento foi possível perceber a importância de incentivar programas educativos e incluir a disciplina de Segurança Contra Incêndio para capacitar os projetistas. Com esse primeiro passo a semente da responsabilidade desses profissionais estaria plantada e consequentemente um avanço nas pesquisas, por meio das universidades.

Com o incentivo às pesquisas e o fortalecimento dos códigos vigentes no Brasil seria possível a aplicação de um código baseado em desempenho, mas para isso é necessário que a população atue como agentes modificadores do cenário atual, cobrando dos órgãos governamentais, em favor de um plano de segurança contra incêndios nas edificações.

No decorrer do trabalho, identificou-se que cada autor, projetista, usuário, proprietário deve contribuir com suas responsabilidades para promover a segurança contra incêndios. Ressalta-se que, mais importante do que aprovar um projeto, é que este atenda o objetivo principal, que é garantir que a edificação funcione como instrumento para proteção e preservação da vida de seus usuários. 
Revista Científica do Corpo de Bombeiros Militar de Pernambuco

Artigo publicado no Vol.05 Nº12 - Edição de JAN a JUN 2019 - ISSN 2359-4829

Versão on-line disponível em: http://www.revistaflammae.com.

Por fim, sugere-se para trabalhos futuros, que haja o aprofundamento dos assuntos apresentados neste trabalho bem como a busca de melhorias dos métodos de elaboração, análise, aprovação e execução de projetos relacionados à prevenção contra incêndios e pânico.

\section{REFERÊNCIAS}

BERTO, Antônio F. Tecnologia de Edificações: Proteção Contra Incêndio de Estruturas de Aço. São Paulo: Pini, 1998.

CARDOSO, Luiz Antônio. Prevenção de Incêndios, uma retrospectiva dos primeiros anos das atividades técnicas em Santa Catarina 1973-1993. Florianópolis: Papa-Livro, 2014.

CARLA, A.; SILVA, P. Percepção ao risco de incêndios em Espaços Urbanos Históricos Um estudo de caso no Bairro do Recife . p. 1-8, 2003.

CONCEIÇÃO, A. T. C. A. L. S. DA. Manual de segurança contra incêndio e pânico proteção passiva. 2006.

Diamants, D. (2014).Principles of Fire Prevention.3rd Edition. England: Jones \& Bartlett Learning

DUARTE, D. Projetos Baseados no Desempenho. VI Simpósio, 2002.

G1.GLOBO. Tragédia em boate no RS: o que já se sabe e as perguntas a responder. Incêndio na casa noturna de Santa Maria em 27 de janeiro matou 241.Responsabilidade sobre alvará é um dos principais pontos a esclarecer. Atualizado em 22/03/2013. Disponível em: <http://g1.globo.com/rs/rio-grande-do-sul/noticia/2013/01/tragedia-em-santamaria-o-que-ja-se-sabe-e-perguntas-responder.html>Acesso em 07/11/2018

HAHNEMANN, A.; CORREAA, C.; RABBANI, E. Avaliação de segurança contra incêncio: método alternativo aplicado a edificações brasileiras. Revista ALCONPAT. 2017

Malkawi, Ali M. (2005) Performance simulation: Research and Tools.In: Performative Architecture - Beyond Instrumentality. Ed. Spon Press, London, UK. 
NARLOCH, Tamyres Blenke; LIMA, Mayara Amin De; SOUZA, João Carlos. Levantamento de requisitos do projeto preventivo de incêndio que impactam no projeto arquitetônico. XXI SIMPEP - Bauru-SP. 2014.

ONO, Rosaria. Parâmetros para garantia da qualidade do projeto de segurança contra incêndio em edifícios altos. Ambiente Construído, v. 7, n. 1, p. 97-113, 2007.

ROBERTSON, J. C. (2005)Introduction to Fire Prevention. Sixth Edit ed.Prentice Hall

SEITO, A. I. et al. A segurança contra incêndio no Brasil. [s.I: s.n.].2008

SERPA, F. B. A segurança contra incêndio como abordagem de conservação do patrimônio histórico edificado: a aplicação do sistema de projeto baseado em desempenho em edifícios históricos em Florianópolis, SC. 2009

SILVA, V. L. DA. Fatores que influenciam o prazo das análises de projetos e vistorias das medidas de segurança contra incêndio/ e pânico realizadas pelo corpo de bombeiros militar de Alagoas. 2017.

SOUZA, J. C. A importância do projeto arquitetônico para a prevenção contra incêndios. 1996.

TAVARES, R. M.; CARLA, A.; SILVA, P. Códigos Prescritivos $x$ Códigos Baseados no Desempenho : Qual é a melhor opção para o contexto do Brasil ? p. 1-8, 2002.

TORERO, J. L.; Prescrição ou Performance: Quando? Porquê? Como? Quem? Revista Sul-Americana de Engenharia Estrutural, Passo Fundo, v. 8, n. 1, jan./abr. 2011

VIEIRA, J. A. A Lei $n^{0}$ 13.425/2017 (Lei Kiss) e a análise acerca da necessidade de expedição de decreto executivo para sua regulamentação. 2018.

MOSER, I. R. Evacuação segura de pessoas em incêndios em edifícios e áreas com interesse histórico. 2018 